\title{
Comparative study: Knowledge and Attitude regarding risks of chewing Khat among Nurses Students at Sabay University College Jazan University 2019
}

\author{
Madeha Ali Mahmoud ${ }^{1}$, Sharifa Mohammed Robah ${ }^{2}$, Ghadeer Hassan Qaisi ${ }^{3}$ \&Ashjan Abdooh Alshwehy ${ }^{4}$ \\ 1. Assistant professor, Medical Surgical Nursing, Faculty of Nursing, Assiut University, Egypt, \\ Assisstant professor ,Sabya University College ,Jazan University, Saudi Arabia. \\ 2. Students in level six Jazan University, Sabya University College, Saudi Arabia. \\ 3. Students in level six Jazan University, Sabya University College, Saudi Arabia. \\ 4. Students in level six Jazan University, Sabya University College, Saudi Arabia.
}

\begin{abstract}
:
Khat chewing is a common habit among the population in the Jazan regions. Aim of the study: To identify the knowledge and attitude of nursing and non-nursing students as regard risks of chewing Khat and to perform a comparison between attitude and knowledge of nursing and non-nursing students as regard risks of chewing Khat. Study design and setting: Descriptive design was utilized on 323 students in the Sabay University College at Jazan University Kingdom of Saudi Arabia. Method: Data were collected by using a self-administered questionnaire about knowledge, risks, and attitude of nursing and non-nursing students regarding risks of chewing Khat. Results: Shows that about one-third of students are in (computer science, Accounting, and Nursing) departments with percentages $(32.5 \%, 31.9 \%$ and $35.6 \%)$ respectively. And more than half $(59.2 \%)$ of students in accounting study have a poor knowledge level and more than one-third (38.3\%) of nursing students have a poor knowledge as regarding risks of chewing Khat. Conclusion: The study found that nursing and non-nursing students had a poor knowledge level as well as a negative attitude toward khat chewing. Recommendations: Implementing an educational program for students could increase knowledge, and awareness among university students and reduce the prevalence of the habit and its unfavorable consequences.
\end{abstract}

Keywords: Attitude, Chewing Khat, Knowledge, Risks \& Students

\section{Introduction:}

Khat may be harmful when consumed by mouth, to most people. Mood changes, increased alertness, excessive talkativeness, hyperactivity, excitement, aggressiveness, anxiety, elevated blood pressure, manic behaviour, paranoia, and psychoses are all possible adverse effects, despite the fact that it isn't linked to physical addiction Hoffman (2013) Insomnia (difficulty sleeping) with memory loss could also occur due to chowing khat Nakajima et al., (2014).

Khat, kat, chat, quat, catha, tschat, miraa, African salad, African tea, Abyssinian tea, kuses-salahin, and tohai are some of the numerous names and spellings for Khat (pronounced cot). The leaf is from a tiny evergreen shrub that can reach tree-like proportions Colzato et al., (2011).

According to Berhanu et al., (2012) the current prevalence of khat among the general population in the Jazan area is $48.7 \%$. (45.7 percent in rural areas, compared to $61.7 \%$ in urban areas), while in Sabiya around (72.5\%), Jazan (61.7\%), Alhurath (58.1\%), Abu Arish (56.8\%), and Samtah (72.5\%), were among the provinces where it was widely used are around $(55.7 \%)$.
Chewing khat was linked to less working hours, a greater average number of serious road traffic accidents, and a higher frequency of traffic violations. Furthermore, khat chewing has been associated with a decrease working abilities and productivity, family problems, and criminal convictions Awadalla \& Suwaydi (2017).

Despite the negative elements of khat chewing and legal constraints, the habit of khat chewing is widespread among large segments of the Jazan population. Kassa, et al., (2017 )The proximity of Jazan to Yemen, where khat is grown and widely eaten, contributed greatly to khat availability in the region through border smuggling. Since 1957, when khat chewing was made illegal, However, neither development efforts nor draconic retribution in the Faifa Mountains, where khat is grown locally, have diminished the region's khat chewing rates. Gatter (2012) \& Al-sanosy et al., (2013).

To lower prevalence of khat usage, the government and non-governmental groups should establish and improve community preventive programmes Berhan et al., (2013).

Significance of the study:

There are a variety of reasons why university students are forced to chew khat during study or exam periods. 
As a consequence, this study gathering data on students' knowledge and attitudes towards khat will provide insight into the prevalence of this harmful practice among them. And to concern for the risks of chewing Khat and importance of avoid this habit among the large segments of the Jazan population.

Aim of the study:

To identify the knowledge and attitude of nursing and non-nursing students as regard risks of chewing Khat and to perform a comparison between attitude and knowledge of nursing and non-nursing students as regard risks of chewing Khat.

\section{Research questions:}

1. What level of knowledge and attitude do nursing and non-nursing students have about the dangers of chewing Khat?

2. Is there a difference between attitude and level of knowledge among nursing and non-nursing students when it comes to the dangers of chewing Khat?

\section{Subjects and Method:}

Study Design: Descriptive, comparative research design was utilized to carry out this study.

Setting: This study was conducted in Sabay University College at Jazan University.

Sampling:

Convenience sample of the student consisted of (323) student

Inclusion criteria: female students at study level from fourth to seventh from colleges of computer science, accounting, and nursing.

Convenient sample including all the available students in the previse mention colleges by the following consequences [Computer science (105) and Accounting (103) and Nursing (115)]

\section{Tools of data collection}

Tool I: Self-administered questionnaire:

It was developed by the researchers based on the recent national and international literature. It included 3parts:

Part I: Student's locations assessment: This included questions to identify student's study college and levels according to inclusion criteria; the demographic data included the following (all female students at study level from (fourth to seventh)?? at the age ranged from 16 and $\mathbf{1 7}$ years with all social class, from colleges of computer science, accounting, and nursing.

Parts II: Students' level of knowledge about chewing khat and risks of chewing khat: This part included questions about the definition of khat, health benefits of chewing khat, signs of abusing khat, the rapid effect of chewing khat on the nervous system, the psychological damage of chewing khat, and its relation to cancer development.

Also, this part included questions about knowledge related risks of chewing Khat on the teeth, tongue, throat, esophagus, stomach \& duodenum, intestine, liver, constipation, hemorrhoids, appetite, nutrition, urinary system, thyroid /endocrine system, and testosterone hormone

\section{Scoring system:}

Each right answer was given one score. The total scores were 21 degree. Those who obtained less than $50 \%$ (less than 10.5 degrees) were considered having un satisfactory level of knowledge. While those who obtained 50\%-70\% (10.5- 14.5 degrees) were considered having fair level and more than $70 \%$ (more than 14.5 degrees) were considered having satisfactory level of knowledge.

Parts III: Students' attitude toward chewing Khat: This part included five questions as ( behavior towards chewing khat if given the opportunity? behavior towards chewing khat from someone you know?, Does chewing khat have social harms?, Does chewing khat have religious harms?, and Does chewing khat have economic harms?)

\section{Scoring system:}

The answers were evaluated by 2-point Likert rating scale ranging from agree (score 2) to disagree (score 1). The total of attitude scores as well as barrier scores for each student were computed as a sum of the total number scores (2-point Likert) answered for the questions. The total items were 5 . Those who obtained less than ( 3 score) were considered having a negative attitude. While, those who obtained more than 3 score were considered having a positive attitude

Validity of the Tools

Five specialists from the Medical-Surgical Nursing Department's nursing faculty reviewed the study tools. The tool was evaluated for clarity, relevance, application, comprehension, and understanding by the expert. Changes have been made in response to their suggestions.

Reliability of the tools: Person Separation Index (PSI) indicates the extent to which the questionnaire distinguishes distinct ability levels. This is equivalent to Cronbach's alpha, with values $\geq 0.80$ regarded as adequate.

\section{Ethical considerations:}

The research was approved by the ethical committee of the respective colleges. Any participant had the choice to quit from the study at any point. The collected data's privacy and secrecy, anonymity, and protection were all ensured. The end output was used for both publication and education. 
Study procedure:

- The researcher obtains permission from the teaching staff and introduced herself to the students and explained the purpose of the study, as well as she asked the participant about the possibility to join the study. The study started in March 2020 to May 2020 at the same time in all study sitting .

- A pilot study of $10 \%$ of the study sample about 20 students to ensure the applicability of the questionnaire.

- Those student who were included in the pilot study were included in the main study as no modifications were done in the study tools .

- Based on the recent and scientific research cycle, data was collected to assess students' level of knowledge, risks, and attitude regarding chewing of khat by using a self-administered questionnaire.
- The researcher distributed the self-administered questionnaire to each subject in the study class and asked them to fill the questionnaire completely and honestly. After that, the researcher collected the questionnaire from the students. The collection of data took three months in each study setting.

Data analysis

Data analysis don by using the Statistical Package for the Social Sciences (SPSSVR) version 18.0 (SPSS Inc. Released 2009). It was used to analyses the data collected from the surveys. Version 18.0 of PASW Statistics for Windows. SPSS Inc., Chicago. For each variable, the frequency was calculated. By using One Way ANOVAs and Chi-square, test for qualitative data between the two groups.

\section{Results:}

Table (1): Comparison of the studied sample according to department and level of the study $(\mathrm{N} .=323)$ :

\begin{tabular}{|l|c|c|}
\hline \multicolumn{1}{|c|}{ Department } & $(\mathbf{N . = 3 2 3})$ & \% \\
\hline computer science & 105 & 32.5 \\
\hline Accounting & 103 & 31.9 \\
\hline Nursing & 115 & 35.6 \\
\hline Study Level: & & \\
\hline Fourth & 85 & 26.3 \\
\hline Fifth & 101 & 31.3 \\
\hline Sixth & 55 & 17.0 \\
\hline Seventh & 82 & 25.4 \\
\hline
\end{tabular}

Table (2): Comparison distribution of the studied sample level of knowledge about chewing Khat $(\mathbf{N}$. = 323):

\begin{tabular}{|c|c|c|c|c|c|c|c|c|c|}
\hline \multirow{2}{*}{$\begin{array}{c}\text { Knowledge } \\
\text { about chewing } \\
\text { Khat }\end{array}$} & \multicolumn{2}{|c|}{$\begin{array}{c}\text { Computer science } \\
(n=105)\end{array}$} & \multicolumn{2}{|c|}{$\begin{array}{c}\text { Accounting } \\
(n=103)\end{array}$} & \multicolumn{2}{|c|}{$\begin{array}{l}\text { Nursing } \\
(n=115)\end{array}$} & \multicolumn{2}{|c|}{$\begin{array}{c}\text { Total } \\
\mathbf{n}=(\mathbf{3 2 3})\end{array}$} & \multirow[t]{2}{*}{ P. value } \\
\hline & No & $\%$ & No & $\%$ & No & $\%$ & No & $\%$ & \\
\hline \multicolumn{10}{|l|}{ What is khat } \\
\hline Incorrect & 0 & 0.0 & 0 & 0.0 & 0 & 0.0 & 0 & 0.0 & \multirow{2}{*}{-} \\
\hline Correct & 105 & 100.0 & 103 & 100.0 & 115 & 100.0 & 323 & 100.0 & \\
\hline \multicolumn{10}{|c|}{ What are the health benefits of chewing khat? } \\
\hline Incorrect & 11 & 10.5 & 29 & 28.2 & 12 & 10.4 & 52 & 16.1 & \multirow{2}{*}{$<0.001 * *$} \\
\hline Correct & 94 & 89.5 & 74 & 71.8 & 103 & 89.6 & 271 & 83.9 & \\
\hline \multicolumn{10}{|c|}{ What are the signs of khat abuse? } \\
\hline Incorrect & 94 & 89.5 & 72 & 69.9 & 92 & 80.0 & 258 & 79.9 & \multirow{2}{*}{$<0.001 * *$} \\
\hline Correct & 11 & 10.5 & 31 & 30.1 & 23 & 20.0 & 65 & 20.1 & \\
\hline \multicolumn{10}{|c|}{ What is the rapid effect of chewing khat on the nervous system? } \\
\hline Incorrect & 104 & 99.0 & 77 & 74.8 & 108 & 93.9 & 289 & 89.5 & \multirow{2}{*}{$<0.001 * *$} \\
\hline Correct & 1 & 1.0 & 26 & 25.2 & 7 & 6.1 & 34 & 10.5 & \\
\hline \multicolumn{10}{|c|}{ What is the rapid effect of chewing khat on the nervous system } \\
\hline Incorrect & 91 & 86.7 & 103 & 100.0 & 115 & 100.0 & 309 & 95.7 & \multirow{2}{*}{$<0.001 * *$} \\
\hline Correct & 14 & 13.3 & 0 & 0.0 & 0 & 0.0 & 14 & 4.3 & \\
\hline \multicolumn{10}{|c|}{ Does chewing khat have psychological damage? } \\
\hline Incorrect & 51 & 48.6 & 81 & 78.6 & 36 & 31.3 & 168 & 52.0 & \multirow{2}{*}{$<0.001 * *$} \\
\hline Correct & 54 & 51.4 & 22 & 21.4 & 79 & 68.7 & 155 & 48.0 & \\
\hline \multicolumn{10}{|c|}{ Is chewing khat has relation to cancer? } \\
\hline Incorrect & 76 & 72.4 & 82 & 79.6 & 30 & 26.1 & 188 & 58.2 & \multirow{2}{*}{$<0.001 * *$} \\
\hline Correct & 29 & 27.6 & 21 & 20.4 & 85 & 73.9 & 135 & 41.8 & \\
\hline
\end{tabular}

Chi-square test for qualitative data between the two groups

$* *$ Significant level at $P$-value $<0.01$ 
Table (3): Comparison of the studied sample level of knowledge about risks of chewing Khat $(\mathrm{N} .=323)$ :

\begin{tabular}{|c|c|c|c|c|c|c|c|c|c|}
\hline \multirow{2}{*}{$\begin{array}{l}\text { Knowledge } \\
\text { about risks of } \\
\text { chewing khat }\end{array}$} & \multicolumn{2}{|c|}{$\begin{array}{c}\text { Computer } \\
\text { science } \\
(\mathbf{n}=\mathbf{1 0 5})\end{array}$} & \multicolumn{2}{|c|}{$\begin{array}{l}\text { Accounting } \\
\quad(n=103)\end{array}$} & \multicolumn{2}{|c|}{$\begin{array}{l}\text { Nursing } \\
(n=115)\end{array}$} & \multicolumn{2}{|c|}{$\begin{array}{c}\text { Total } \\
n=(323)\end{array}$} & \multirow[t]{2}{*}{ P. value } \\
\hline & No & $\%$ & No & $\%$ & No & $\%$ & No & $\%$ & \\
\hline \multicolumn{10}{|l|}{ The teeth } \\
\hline Incorrect & 103 & 98.1 & 78 & 75.7 & 24 & 20.9 & 205 & 63.5 & \multirow{2}{*}{$<0.001 * *$} \\
\hline Correct & 2 & 1.9 & 25 & 24.3 & 91 & 79.1 & 118 & 36.5 & \\
\hline \multicolumn{10}{|l|}{ The tongue } \\
\hline Incorrect & 105 & 100.0 & 61 & 59.2 & 26 & 22.6 & 192 & 59.4 & \multirow{2}{*}{$<0.001 * *$} \\
\hline Correct & 0 & 0.0 & 42 & 40.8 & 89 & 77.4 & 131 & 40.6 & \\
\hline \multicolumn{10}{|l|}{ Throat } \\
\hline Incorrect & 105 & 100.0 & 61 & 59.2 & 26 & 22.6 & 192 & 59.4 & \multirow{2}{*}{$<0.001 * *$} \\
\hline Correct & 0 & 0.0 & 42 & 40.8 & 89 & 77.4 & 131 & 40.6 & \\
\hline \multicolumn{10}{|l|}{ Esophagus } \\
\hline Incorrect & 105 & 100.0 & 61 & 59.2 & 26 & 22.6 & 192 & 59.4 & \multirow{2}{*}{$<0.001 * *$} \\
\hline Correct & 0 & 0.0 & 42 & 40.8 & 89 & 77.4 & 131 & 40.6 & \\
\hline \multicolumn{10}{|c|}{ Stomach \&duodenum } \\
\hline Incorrect & 105 & 100.0 & 61 & 59.2 & 23 & 20.0 & 189 & 58.5 & \multirow{2}{*}{$<0.001 * *$} \\
\hline Correct & 0 & 0.0 & 42 & 40.8 & 92 & 80.0 & 134 & 41.5 & \\
\hline \multicolumn{10}{|l|}{ Intestine } \\
\hline Incorrect & 105 & 100.0 & 61 & 59.2 & 26 & 22.6 & 192 & 59.4 & \multirow{2}{*}{$<0.001 * *$} \\
\hline Correct & 0 & 0.0 & 42 & 40.8 & 89 & 77.4 & 131 & 40.6 & \\
\hline \multicolumn{10}{|l|}{ Liver } \\
\hline Incorrect & 103 & 98.1 & 61 & 59.2 & 57 & 49.6 & 221 & 68.4 & \multirow{2}{*}{$<0.001 * *$} \\
\hline Correct & 2 & 1.9 & 42 & 40.8 & 58 & 50.4 & 102 & 31.6 & \\
\hline \multicolumn{10}{|l|}{ Constipation } \\
\hline Incorrect & 105 & 100.0 & 60 & 58.3 & 66 & 57.4 & 231 & 71.5 & \multirow{2}{*}{$<0.001 * *$} \\
\hline Correct & 0 & 0.0 & 43 & 41.7 & 49 & 42.6 & 92 & 28.5 & \\
\hline Hemorrhoids & & & & & & & & & \\
\hline Incorrect & 105 & 100.0 & 60 & 58.3 & 68 & 59.1 & 233 & 72.1 & $<0001 * *$ \\
\hline Correct & 0 & 0.0 & 43 & 41.7 & 47 & 40.9 & 90 & 27.9 & 0.001 \\
\hline Appetite & & & & & & & & & \\
\hline Incorrect & 105 & 100.0 & 60 & 58.3 & 63 & 54.8 & 228 & 70.6 & $<0001 * *$ \\
\hline Correct & 0 & 0.0 & 43 & 41.7 & 52 & 45.2 & 95 & 29.4 & 0.001 \\
\hline Nutrition & & & & & & & & & \\
\hline Incorrect & 105 & 100.0 & 60 & 58.3 & 63 & 54.8 & 228 & 70.6 & \\
\hline Correct & 0 & 0.0 & 43 & 41.7 & 52 & 45.2 & 95 & 29.4 & \\
\hline Urinary system & & & & & & & & & $<0.001 * *$ \\
\hline Incorrect & 105 & 100.0 & 60 & 58.3 & 63 & 54.8 & 228 & 70.6 & \\
\hline Correct & 0.0 & 0.0 & 43 & 41.7 & 52 & 45.2 & 95 & 29.4 & \\
\hline Thyroid/Endoc & & & & & & & & & \\
\hline Incorrect & 105 & 100.0 & 61 & 59.2 & 74 & 64.3 & 240 & 74.3 & $<0.001 * *$ \\
\hline Correct & 0 & 0.0 & 42 & 40.8 & 41 & 35.7 & 83 & 25.7 & \\
\hline Testosterone $\mathrm{Ho}$ & none & & & & & & & & \\
\hline Incorrect & 105 & 100.0 & 61 & 59.2 & 74 & 64.3 & 240 & 74.3 & $<0001 * *$ \\
\hline Correct & 0 & 0.0 & 42 & 40.8 & 41 & 35.7 & 83 & 25.7 & \\
\hline
\end{tabular}

Chi-square test for qualitative data between the two groups

**Significant level at P-value $<0.01$ 
Table (4): Comparison of the studied sample regarding their attitude toward chewing Khat $\left(\mathrm{N}_{\text {. }}=323\right)$ :

\begin{tabular}{|c|c|c|c|c|c|c|c|c|c|}
\hline \multirow{2}{*}{$\begin{array}{l}\text { Attitude toward } \\
\text { chewing khat }\end{array}$} & \multicolumn{2}{|c|}{$\begin{array}{c}\text { Computer science } \\
(n=105)\end{array}$} & \multicolumn{2}{|c|}{$\begin{array}{c}\text { Accounting } \\
(n=103)\end{array}$} & \multicolumn{2}{|c|}{$\begin{array}{c}\text { Nursing } \\
(n=115)\end{array}$} & \multicolumn{2}{|c|}{$\begin{array}{c}\text { Total } \\
\mathbf{n}=(\mathbf{3 2 3})\end{array}$} & \multirow[t]{2}{*}{ P. value } \\
\hline & No & $\%$ & No & $\%$ & No & $\%$ & No & $\%$ & \\
\hline \multicolumn{10}{|c|}{ Behavior towards chewing khat if given the opportunity? } \\
\hline Disagree & 57 & 54.3 & 57 & 55.3 & 37 & 32.2 & 151 & 46.7 & \multirow{2}{*}{$<0.001 * *$} \\
\hline Agree & 48 & 45.7 & 46 & 44.7 & 78 & 67.8 & 172 & 53.3 & \\
\hline \multicolumn{10}{|c|}{ Behavior towards chewing khat from someone you know? } \\
\hline Disagree & 61 & 58.1 & 60 & 58.3 & 18 & 15.7 & 139 & 43.0 & \multirow{2}{*}{$<0.001 * *$} \\
\hline Correct & 44 & 41.9 & 43 & 41.7 & 97 & 84.3 & 184 & 57.0 & \\
\hline \multicolumn{10}{|c|}{ Does chewing khat have social harm? } \\
\hline Disagree & 101 & 96.2 & 45 & 43.7 & 19 & 16.5 & 165 & 51.1 & \multirow{2}{*}{$<0.001 * *$} \\
\hline Agree & 4 & 3.8 & 58 & 56.3 & 96 & 83.5 & 158 & 48.9 & \\
\hline \multicolumn{10}{|c|}{ Does chewing khat have religious harm? } \\
\hline Disagree & 105 & 100.0 & 51 & 49.5 & 50 & 43.5 & 206 & 63.8 & \multirow{2}{*}{$<0.001 * *$} \\
\hline Agree & 0 & 0.0 & 52 & 50.5 & 65 & 56.5 & 117 & 36.2 & \\
\hline \multicolumn{10}{|c|}{ Does chewing khat have economic harm? } \\
\hline Disagree & 53 & 50.5 & 5 & 4.9 & 14 & 12.2 & 72 & 22.3 & \multirow{2}{*}{$<0.001 * *$} \\
\hline Agree & 52 & 49.5 & 98 & 95.1 & 101 & 87.8 & 251 & 77.7 & \\
\hline
\end{tabular}

Chi-square test for qualitative data between the two groups

-**Significant level at $P$ value $<0.01$

Table (5): Relationship between total students' level of knowledge about khat and study sample location or department or collages $n=(323)$

\begin{tabular}{|c|c|c|c|c|c|c|c|c|c|c|}
\hline \multirow{2}{*}{$\begin{array}{c}\text { Students' } \\
\text { knowledge about } \\
\text { khat }\end{array}$} & \multirow{2}{*}{$\begin{array}{c}\text { Max } \\
\text { Score }\end{array}$} & \multicolumn{2}{|c|}{$\begin{array}{c}\text { Computer science } \\
(\mathrm{n}=\mathbf{1 0 5})\end{array}$} & \multicolumn{2}{|c|}{$\begin{array}{c}\text { Accounting } \\
(\mathbf{n}=\mathbf{1 0 3})\end{array}$} & \multicolumn{2}{|c|}{$\begin{array}{l}\text { Nursing } \\
(n=115)\end{array}$} & \multicolumn{2}{|c|}{$\begin{array}{c}\text { Total } \\
n=(323)\end{array}$} & \multirow[t]{2}{*}{ P. value } \\
\hline & & No & $\%$ & No & $\%$ & No & $\%$ & No & $\%$ & \\
\hline Poor & $<50 \%$ & 105 & 100.0 & 61 & 59.2 & 44 & 38.3 & 210 & 65.0 & \multirow{3}{*}{$<0.001 * *$} \\
\hline Faire & $50-70 \%$ & 0 & 0.0 & 15 & 14.6 & 38 & 33.0 & 53 & 16.4 & \\
\hline Good & $>70 \%$ & 0 & 0.0 & 27 & 26.2 & 33 & 28.7 & 60 & 18.6 & \\
\hline Mean \pm SD & 21 & \multicolumn{2}{|c|}{$2.97 \pm 1.22$} & \multicolumn{2}{|c|}{$8.28 \pm 6.01$} & \multicolumn{2}{|c|}{$11.68 \pm 3.86$} & \multicolumn{2}{|c|}{$7.76 \pm 5.5$} & $<0.001 * *$ \\
\hline
\end{tabular}

-Chi-square test for qualitative data between the two groups $\quad$-**Significant level at P-value $<0.01$

- One Way ANOVAs for quantitative data between the three groups or more

Table (6): Relationship between total students' attitude about khat and their study collage $\mathbf{n}=(323)$

\begin{tabular}{|c|c|c|c|c|c|c|c|c|c|c|}
\hline \multirow{2}{*}{$\begin{array}{l}\text { students' attitude } \\
\text { about khat }\end{array}$} & \multirow{2}{*}{$\begin{array}{c}\text { Max } \\
\text { Score }\end{array}$} & \multicolumn{2}{|c|}{$\begin{array}{c}\text { Computer science } \\
(\mathbf{n}=\mathbf{1 0 5})\end{array}$} & \multicolumn{2}{|c|}{$\begin{array}{l}\text { Accounting } \\
(\mathbf{n}=\mathbf{1 0 3})\end{array}$} & \multicolumn{2}{|c|}{$\begin{array}{l}\text { Nursing } \\
(n=115)\end{array}$} & \multicolumn{2}{|c|}{$\begin{array}{c}\text { Total } \\
n=(323)\end{array}$} & \multirow[t]{2}{*}{ P. value } \\
\hline & & No & $\%$ & No & $\%$ & No & $\%$ & No & $\%$ & \\
\hline Negative Attitude & $<60 \%$ & 98 & 93.3 & 27 & 26.2 & 29 & 25.2 & 154 & 47.7 & \\
\hline Positive Attitude & $>60 \%$ & 7 & 6.7 & 76 & 73.8 & 86 & 74.8 & 169 & 52.3 & $<0.001 * *$ \\
\hline Mean \pm SD & 5 & \multicolumn{2}{|c|}{$1.41 \pm 0.83$} & \multicolumn{2}{|c|}{$2.88 \pm 0.99$} & \multicolumn{2}{|c|}{$3.8 \pm 1.55$} & \multicolumn{2}{|c|}{$2.73 \pm 1.54$} & $<0.001 * *$ \\
\hline
\end{tabular}

Chi-square test for qualitative data between the two groups

- One Way ANOVAs for quantitative data between the three groups or more

**Significant level at P-value $<0.01$

Table (7): Relationship between students total level of knowledge about khat and students' study level $\mathrm{n}=(323)$

\begin{tabular}{|c|c|c|c|c|c|c|c|c|c|c|c|}
\hline \multirow{2}{*}{$\begin{array}{l}\text { students' total } \\
\text { Knowledge } \\
\text { about khat }\end{array}$} & \multicolumn{2}{|c|}{$\begin{array}{r}\text { Fourth } \\
(\mathrm{N}=85)\end{array}$} & \multicolumn{2}{|c|}{$\begin{array}{c}\text { Fifth } \\
(\mathrm{N}=101)\end{array}$} & \multicolumn{2}{|c|}{$\begin{array}{l}\text { Sixth } \\
(\mathbf{N}=55)\end{array}$} & \multicolumn{2}{|c|}{$\begin{array}{r}\text { Seventh } \\
(\mathrm{N}=82)\end{array}$} & \multicolumn{2}{|c|}{$\begin{array}{c}\text { Total } \\
(\mathbf{N}=\mathbf{3 2 3})\end{array}$} & \multirow[t]{2}{*}{ P. value } \\
\hline & No & $\%$ & No & $\%$ & No & $\%$ & No & $\%$ & No & $\%$ & \\
\hline Poor & 48 & 56.5 & 56 & 55.4 & 38 & 69.1 & 68 & 82.9 & 210 & 65.0 & \multirow{3}{*}{$<0.001 * *$} \\
\hline Faire & 19 & 22.4 & 25 & 24.8 & 9 & 16.4 & 0 & 0.0 & 53 & 16.4 & \\
\hline Good & 18 & 21.2 & 20 & 19.8 & 8 & 14.5 & 14 & 17.1 & 60 & 18.6 & \\
\hline Mean \pm SD & \multicolumn{2}{|c|}{$7.93 \pm 5.51$} & \multicolumn{2}{|c|}{$8.57 \pm 4.67$} & \multicolumn{2}{|c|}{$6.67 \pm 6.19$} & \multicolumn{2}{|c|}{$7.33 \pm 5.87$} & \multicolumn{2}{|c|}{$7.76 \pm 5.5$} & $<0.001 * *$ \\
\hline
\end{tabular}

Chi-square test for qualitative data between the two groups

- One Way ANOVAs for quantitative data between the three groups or more

-**Significant level at $P$-value $<0.01$ 
Table (8): Relationship between students' attitude toward khat and students study level $\mathbf{n}=(323)$

\begin{tabular}{|c|c|c|c|c|c|c|c|c|c|c|c|}
\hline \multirow[t]{2}{*}{$\begin{array}{l}\text { students' attitude } \\
\text { about khat }\end{array}$} & \multicolumn{2}{|c|}{$\begin{array}{c}\text { Fourth } \\
(\mathrm{N}=85)\end{array}$} & \multicolumn{2}{|c|}{$\begin{array}{c}\text { Fifth } \\
(\mathrm{N}=101)\end{array}$} & \multicolumn{2}{|c|}{$\begin{array}{c}\text { Sixth } \\
(\mathbf{N}=55)\end{array}$} & \multicolumn{2}{|c|}{$\begin{array}{c}\text { Seventh } \\
(\mathrm{N}=82)\end{array}$} & \multicolumn{2}{|c|}{$\begin{array}{c}\text { Total } \\
(\mathbf{N}=\mathbf{3 2 3}) \\
\end{array}$} & \multirow[t]{2}{*}{ P. value } \\
\hline & No & $\%$ & No & $\%$ & No & & No & $\%$ & No & $\%$ & \\
\hline Negat & 52 & 61.2 & 45 & $\overline{44.6}$ & 13 & 23. & 44 & 53.7 & 154 & 47.7 & \\
\hline Positive Attitude & 33 & 38.8 & 56 & 55.4 & 42 & 76.4 & 38 & 46.3 & 169 & 52.3 & \\
\hline Mean \pm SD & \multicolumn{2}{|c|}{$2.69 \pm 1.7$} & \multicolumn{2}{|c|}{$2.89 \pm 1.65$} & \multicolumn{2}{|c|}{$3.45 \pm 1.09$} & \multicolumn{2}{|c|}{$2.09 \pm 1.22$} & \multicolumn{2}{|c|}{$2.73 \pm 1.54$} & $<0.001 * *$ \\
\hline
\end{tabular}

Chi-square test for qualitative data between the two groups $\quad$-**Significant level at P-value $<0.01$

- One Way ANOVAs for quantitative data between the three groups or more

Table (1): Shows that the studied sample distributed about one-third of students are in (computer science, Accounting, and Nursing) departments with percentages $(32.5 \%, 31.9$, and $35.6 \%)$ respectively. About one-third $(31.3 \%)$ of students are at level five of study.

Table (2): Clarify that the majority of studied sample get an incorrect answer in all items of knowledge about chewing khat except the first question which about the definition of khat with statistically significant differences with (p. value $<0.001 * *$ ) in each question.

Table (3): Investigate that the majority of the participants in the study give inaccurate answers to all of the items on the risks of chewing khat, with statistically significant differences (p. value $(0.001 * *)$ for all of the items.

Table (4): Demonstrate that almost half of the study participants have a negative attitude towards chewing khat, with statistically significant differences ( $\mathrm{p}$. value $\left(0.001^{* *}\right)$ for all items.

Table (5): Regarding the relationship between total students' level of knowledge about khat and the study sample departments; the current study explores that all students $(100 \%)$ in computer science collage have a poor knowledge level about khat. More than half $(59.2 \%)$ of students in accounting collage have a poor knowledge level and more than one-third (38.3\%) of nursing students have a poor knowledge level with statistically significant differences with $p$. value $(<0.001 * *)$.

Table (6): Shows that the majority (93.3\%) of student in computer science - have a negative attitude toward khat. While accounting and nursing students have a positive attitude among about two-thirds of them, with statistical significance p. value $<0.001 * *$.

Table (7): Shows statistical significance difference between knowledge level about khat and students' study level with a higher percentage of poor knowledge level among all student's study level with p. value $<0.001 * *$.

Table (8): Shows a statistically significant difference between students' attitude toward khat and student's study level with a higher percentage of negative attitude level at all student's study level with p. value $<0.001 * *$.

\section{Discussion:}

The results of our study explore that all students in computer science have poor knowledge about khat. More than half of students in accounting study have poor knowledge and around one-third of nursing students have poor knowledge. From the researcher point of view the female students nursing may have some back ground of knowledge about the Kate. According to a study done by Alshakka et al., (2020), radical methods must be found to combat the practice of khat chewing and its expansion in Yemen, since "khat consumption not only severely impacts users' health but also limits users' finances and time." Many university students in contemporary society are unconcerned with their health and instead concentrate on their studies and educational pursuits.

The current study results reported that the majority of students have a poor level of knowledge about the risks of chewing Khat on the teeth, tongue, throat, esophagus, Stomach \& duodenum, intestine, liver, constipation, hemorrhoids, appetite, nutrition, urinary system, thyroid /endocrine, and testosterone hormone. Regarding Kaluai (2013) who conducted a study titled "khat chewing practices and knowledge of oral health effects among students in two boys' secondary schools in Meru county" was in the same line with the current study results as she reported that "A greater number of respondents do not know the potential implications of khat chewing. This could be because of ignorance on the part of the students and lack of enlightenment from the scientists".

Furthermore, Omar et al., (2015) \& Bongard et al., (2011) agreed with the findings of the current study, stating that "apart from khat's effect on health status and reproductive health, it is one of the reasons creating socio-economic issues." Social isolation, family disintegration, social obligations neglect, and spending more than half of the domes are among them.

The current study showed that the majority of students in computer science have a negative attitude toward khat. While accounting and nursing, students have a positive attitude in about two-thirds of them. While study done by Alshakka et al., (2020) were in the same line with the current study results. 
This study clarifies that there was a statistical significance difference between knowledge level about khat and students' study level with a higher percentage of poor knowledge level at all student's study level. From the researchers' point of view, this result is accepted as the majority of students had not educated enough about khat and its risks on health so the majority of them had a poor knowledge level in all study level.

The current study reported that a statistically significant difference was found between students' attitude toward khat and student's study level with a higher percentage of negative attitude level at all student's study level. Gebiresilus et al., (2014), \& Mahfouz et al., (2021) were not in the same line with study results as they mentioned that" Despite the positive attitude for the practice of using khat and inconsistencies of case reports on psychological and socio-economic problems related to khat use. As a result of the great prevalence of khat chewing, we can witness multifaceted issues in utilizing khat from various groups of the community."

\section{Conclusion:}

The study concluded that nursing and non-nursing student's knowledge level about chewing khat and its risks were poor. Also, all nursing and non-nursing students have a negative attitude toward khat chewing

\section{Recommendations:}

Based on the finding of this study, the following recommendations were made:

- Educational programs about khat and its risks on health should be provided to students of different study levels at Jazan University.

- Community prevention programs should be adopted to overcome the frequent use of khat in the kingdom.

- Further research studies on larger populations in order to generalize the study results.

Acknowledgments:

Authors wish to express their thanks for the Deanship of Scientific Research, Jazan University, Saudi Arabia for the financially supported for this research through the project number FS10-037

\section{References:}

- Alsanosy, R., Mahfouz, M., \& Gaffar, A. (2013): Khat chewing habit among school students of Jazan region, Saudi Arabia. PloS one, 8(6), e65504.

- Alshakka M., Badulla W.F., Al-Abd N. \& Ibrahim M., (2020): Knowledge and Attitudes on Khat Use among Yemeni
Health Sciences Students, Substance Use \& Misuse, 55:4, 557-563,

- Awadalla, N., \& Suwaydi, H. (2017): Prevalence, determinants, and impacts of khat chewing among professional drivers in Southwestern Saudi Arabia. Eastern Mediterranean health journal, 23(3), 189

- Berhan Y., Hailu D., \& Alano A., (2013): Polysubstance use and its linkage with risky sexual behavior in university students: significance for policymakers and parents. Ethiop Med J. Jan; 51(1):13-23.

- Berhanu D., Go V.F., Ruff A., Celentano D.D., \& Bishaw T., (2012): Khat use among HIV voluntary counseling and testing center clients in Ethiopia. Cult Health Sex; 14(10):1197-212.

- Bongard S., al'Absi M, Khalil N.S., \& Al Habori M. (2011): Khat use and trait anger: effects on affect regulation during an acute stressful challenge. Eur Addict Res.; 17(6):285-91.

- Colzato L.S., Ruiz M.J., van den Wildenberg W.P., \& Hommel B. (2011): Khat use is associated with impaired working memory and cognitive flexibility. PLoS One. ;6(6):p.p 6 02- 602.

- Gatter P. (2012): Politics of Qat-The Role of a Drug in Ruling Yemen. Jemen-Studien vol. 20.1, Ludwig Reichert Verlag Wiesbaden Germany,

- Gebiresilus A., Gebresilus B., Yizengaw S., Sewasew D., \& Mengesha T., (2014): khat use prevalence, causes and its effect on mental health, Bahir-dar, northwest Ethiopia European Scientific Journal August edition vol.10, No.23 P.P 1857 - 7881 (Print) e ISSN 1857- 7431

- Hoffman R., (2013): al'Absi M. Working memory and speed of information processing in chronic khat users: preliminary findings. Eur Addict Res.; Vol.19 No.(1): p.p 1-6.

- Kaluai E. (2013): a community dentistry research project report submitted in partial fulfillment of the requirement for the award of bachelor of dental surgery at the University of Nairobi. https://periodontology.uonbi.ac.ke/sites/defa ult/files/chs/dentalschool/periodontology/em ma\%20kaluai.pdf

- Kassa, A., Loha, E., \& Esaiyas, A. (2017): Prevalence of khat chewing and its effect on academic performance in Sidama zone, Southern Ethiopia. African health sciences, Vol.17 No.(1), P.P 175-185. 
- Mahfouz, M., Rahim, B., Solan, Y., Makeen, A., \& Alsanosy, R. (2021): Khat Chewing Habits in the Population of the Jazan Region, Saudi Arabia: Prevalence and Associated Factors. [online] Academia.edu. Available <https://www.academia.edu/30146812/Khat _Chewing_Habits_in_the_Population_of_the _Jazan_Region_Saudi_Arabia_Prevalence_a nd_Associated_Factors> [Accessed 29 March 2021].

- Nakajima M., Hoffman R., \& Al'Absi M. (2014): Poor working memory and reduced blood pressure levels in concurrent users of khat and tobacco. Nicotine Tob Res., 16(3):279-287.

- Omar Y.S., Jenkins A., Altena M.v., Tuck H., Hynan C., Tohow A., Chopra P., \& Castle D. (2015): Khat Use: What Is the Problem and What Can Be Done? Biomed Res Int.:472302. 